\section{Near-infrared transillumination photography to detect anterior uveal melanomas through black IOLs}

Krohn et al describe a novel photographic technique using near-infrared (NIR) transillumination to detect peripheral anterior choroidal and ciliary body melanomas not visible on slit lamp examination. ${ }^{1}$ The described imaging technique uses a broad spectrum background light source to illuminate the fundus and external photography with a $720-1100 \mathrm{~nm}$ NIR filter to evaluate anterior uveal masses, permitting topographical description of tumour location in relation to the ciliary body and ora serrata. ${ }^{12}$

NIR transillumination photography may serve another essential clinical application as the first diagnostic technique described capable of detecting anterior uveal melanomas in patients implanted with black intraocular lenses (IOLs) who cannot undergo slit lamp examination.

Black IOLs are indicated in patients with intractable diplopia, visual confusion, unsightly leucocoria and a range of neuro-ophthalmic disorders. ${ }^{3}$ Despite high rates of postoperative satisfaction in patients, ${ }^{4}$ their use has been restricted by concerns from ophthalmologists that an inability to visualise the retina may prevent the identification of life-threatening pathology-principally uveal melanomabehind the occlusive IOL. ${ }^{5}$

Morcher black IOLs have been demonstrated to transmit high levels of NIR light. ${ }^{5}$ This property permits high quality imaging of the macula and optic nerve using scanning laser ophthalmoscopy and optical coherence tomography with any imaging system in clinical use. ${ }^{5}$ However, conventional non-contact scanning laser ophthalmoscopy (SLO)/optical coherence tomography (OCT) imaging is restricted to a field $30^{\circ}$ around the foveal centre and cannot detect melanomas located anteriorly in the uveal tract.

Transmission spectra of Morcher black IOLs have demonstrated exponential light transmission from $750 \mathrm{~nm}$, transmitting 99\%-100\% of SLO/OCT scanning wavelength light $(820-870 \mathrm{~nm})$ (figure 1). ${ }^{5}$ 


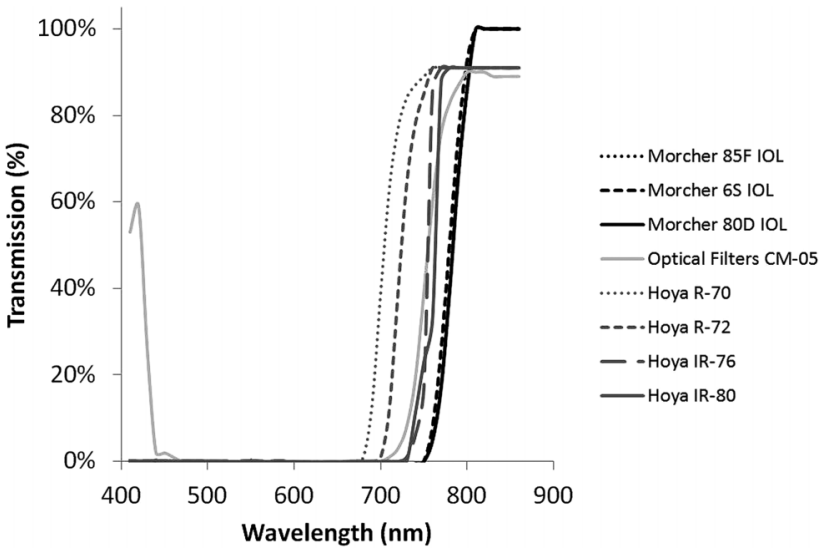

Figure 1 Near-infrared (NIR) transmission characteristics of NIR-transmitting black intraocular lenses (IOLs) and commercial NIR-transmitting filters. Transmission spectra of NIR-transmitting IOLs: ${ }^{5}$ Morcher 85F polymethyl methacrylate (PMMA) IOL (6 mm optic, $12 \mathrm{~mm}$ overall), Morcher 6S PMMA IOL (10 mm optic, $12 \mathrm{~mm}$ overall), Morcher 80D PMMA IOL (6 mm optic, $13.5 \mathrm{~mm}$ overall) and a range of commercially available NIR filters: Optical Filters (CM-05) and Hoya NIR-transmitting filters (R-70, R-72, IR-76, IR-80). Morcher black IOLs demonstrate comparable transmission spectra with NIR filters with more complete NIR-transmission at wavelengths longer than $800 \mathrm{~nm} .^{5}$ Transmission data for NIR filters taken from http://www.optical-filters.com/Cold Mirror_CM-05_Transmission_Data.aspx and http://www.hoyaoptics.com/color_filter/ir_transmitting.htm (Date 30 accessed March 2013).

This NIR window of transmission would enable retinal illumination, as described by Krohn et al, ${ }^{1}$ sufficient to delineate uveal melanomas with an external camera possessing a NIR filter.

Delineation of uveal melanoma through Morcher black IOLs (all models; 85F, 6S, 80D, 34D and 81D) using NIR transillumination photography may be superior

to images acquired in phakic or pseudophakic patients with conventional IOLs described by Krohn et al $1^{1}$ since NIR-transmitting black IOLs would function as NIR filters occluding light transmission below $750 \mathrm{~nm}$ (figure 1)..$^{5}$ This would markedly reduce absorption by chromophores and light scatter from shorter wavelength light while enhancing

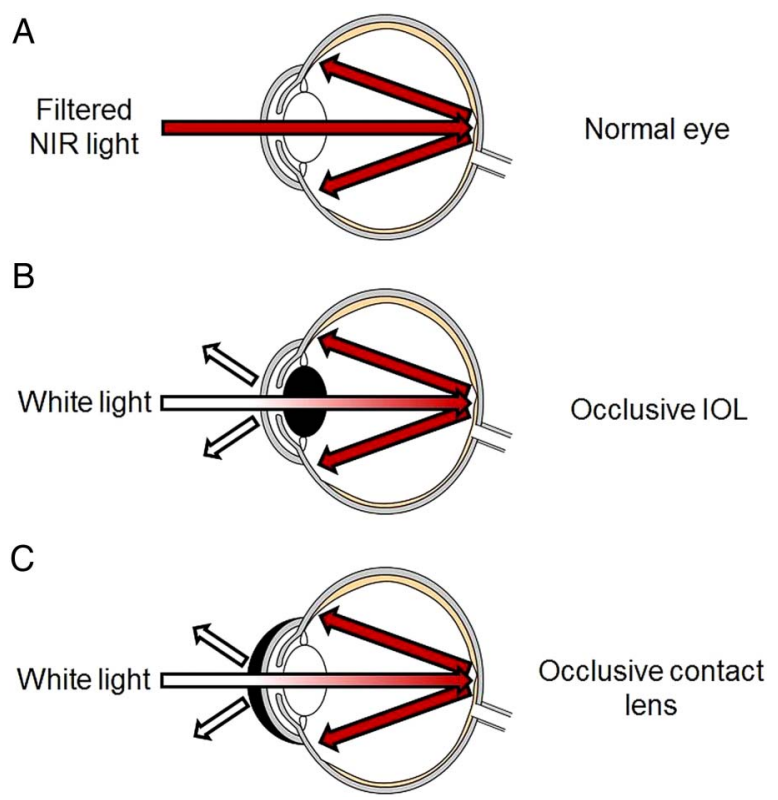

Figure 2 Utility of occlusive intraocular lenses (IOLs) and contact lenses in near-infrared (NIR) transillumination photography. Krohn et al ${ }^{1}$ describe NIR transillumination using a white light without NIR filtration, capturing choroidal details using a camera with NIR filter. We suggest three methods to improve NIR transillumination photography image quality: (A) Use of a NIR filter to eliminate white and ultraviolet light, reducing light scatter from the cornea; (B) Occlusive IOLs as endogenous NIR filters (see figure 1); and (C) Occlusive contact lenses with NIR filtering properties. Occlusive prostheses, as in the technique described by Krohn et al, may produce some light scatter from the anterior corneal interface. This figure is only reproduced in colour in the online version. tissue penetration for clearer topographic delineation of uveal tumours. ${ }^{1}$

Krohn et al suggest the addition of NIR filters on the primary illuminating light source to improve image quality. ${ }^{1}$ Figure 1 illustrates the NIR-transmitting properties of Morcher black IOLs in comparison with commercially available NIR-transmitting filters, demonstrating more complete transmission at wavelengths over $800 \mathrm{~nm}^{5}$ NIR-transmitting black IOLs effectively function as endogenous NIR light filters in this patient group.

We suggest that contact lenses manufactured from optically similar material to NIR-transmitting black IOLs may be incorporated into the imaging protocol to optimise image quality. This would optimise image quality, prevent patient discomfort from broad spectrum light directed flush against the cornea through a dilated pupil (NIR light is not as strongly perceived by patients) and protect the cornea from light source related contact epitheliopathy (figure 2).

NIR transillumination photography fulfils a requirement for an imaging technique to detect anterior uveal melanoma in patients with black IOLs. The combination of conventional non-contact SLO/OCT imaging, ${ }^{5}$ SLO/OCT imaging with a Staurenghi contact lens to enable retinal examination to $150^{\circ 6}$ (Yusuf et al 2013, unpublished manuscript), and NIR transillumination photography should enable light-based detection and evaluation of uveal melanomas at all anatomical locations in patients with implanted black IOLs.

The novel imaging technique of NIR transillumination photography may permit more patients to benefit from black IOL implantation. It is the first light-based imaging technique described capable of detecting anterior uveal melanomas in this patient group.

\section{Imran H Yusuf, ${ }^{1,2}$ Stuart N Peirson, ${ }^{1}$ C K Patel $^{2}$ \\ ${ }^{1}$ Nuffield Laboratory of Ophthalmology, Oxford University, John Radcliffe Hospital, Oxford, UK ${ }^{2}$ The Oxford Eye Hospital, John Radcliffe Hospital, Oxford, UK}

Correspondence to C K Patel, The Oxford Eye Hospital, West Wing, John Radcliffe Hospital, Headley Way, Headington, Oxford OX3 9DU, UK; ckpate|@btinternet.com

Contributors IHY, SNP and CKP wrote the manuscript.

Funding Stuart N Peirson's research is funded in part by the Wellcome Trust. Grant number: HMRSBTO (WTPG).

\section{Competing interests None.}

Provenance and peer review Not commissioned; internally peer reviewed. 


\section{OPEN ACCESS}

Open Access This is an Open Access article distributed in accordance with the Creative Commons Attribution Non Commercial (CC BY-NC 3.0) license, which permits others to distribute, remix, adapt, build upon this work non-commercially, and license their derivative works on different terms, provided the original work is properly cited and the use is non-commercial. See: http:/l creativecommons.org/licenses/by-nc/3.0/

To cite Yusuf IH, Peirson SN, Patel CK. Br J Ophthalmol 2013;97:943-945.

Received 16 April 2013

Accepted 22 April 2013

Published Online First 18 May 2013

Br J Ophthalmol 2013;97:943-945.

doi:10.1136/bjophthalmol-2013-303574

\section{REFERENCES}

1 Krohn J, Ulltang E, Kjersem B. Near-infrared transillumination photography of intraocular tumours. Br J Ophthalmol Published Online First: 26 March 2013. doi:10.1136/bjophthalmol-2013-303090

2 Krohn J, Kjersem B. A modified digital slit lamp camera system for transillumination photography of intraocular tumours. Br J Ophthalmol 2012;96:475-7.

3 Wong SC, Islam N, Ficker L. Black occlusive IOLs. Ophthalmology 2007;114:2365.

4 Hadid OH, Wride NK, Griffiths PG, et al. Opaque intraocular lens for intractable diplopia: experience and patients' expectations and satisfaction. $\mathrm{Br} J$ Ophthalmol 2008;92:912-15.

5 Yusuf IH, Peirson SN, Patel CK. Occlusive IOLs for intractable diplopia demonstrate a novel near-infrared window of transmission for SLO/OCT imaging and clinical assessment. Invest Ophthalmol Vis Sci 2011;52:3737-43.

6 Staurenghi G, Viola F, Mainster MA, et al. Scanning laser ophthalmoscopy and angiography with a wide-field contact lens system. Arch Ophthalmol 2005;123:244-52. 